This presentation will describe the key components of the campaign, including identifying key partners and how each contributed to addressing the injury issue from all angles - regulation, product design, packaging, education and awareness.

15,000 pamphlets were distributed throughout education and health providers, home visitors and care givers to families around the country. 240 kits to demonstrate the risks of the product and how the injury can be prevented were provided to organisations and government services. $90 \%$ of the resource users evaluated the material as effective and very effective and that they learnt a lot about the issue.

The presentation also describes the different mediums and technology used to reach the right audience.

Conclusions Outcomes to date include support from the then Ministers of Health and Consumer Affairs, International recognition for New Zealand as a world-leader in button battery child injury prevention, strong media support and heightened public awareness of the injury issue.

\section{MACHINE SAFETY REGULATION IN THE EU AND THE US}

Juha Vasara, Jouni Kivistö-Rahnasto. Tampere University of Technology, Finland

\subsection{6/injuryprev-2016-042156.349}

Background This paper discusses the results of a study focusing on the differences of regulation around product safety, especially machines for use at work, between the European Union (EU) and the United States of America (US). Authors analyse how the differences effect on European companies manufacturing machines for use at work and what kind of compliance management practices the companies have to tackle the differing regulation.

Methods The results of the study were gathered by literature review and interviews. The semi-structured interviews were conducted to representatives of six globally operating companies manufacturing machines for use at work and to representatives of organisations formulating and/or influencing EU legislation and standardisation.

Results European integration has clarified the companies' operations significantly within the EU. At present the legislation and standards on machinery are mostly harmonised. By contrast the European companies consider that US market is difficult because of the state-specific regulation and completely different framework to consider safety issues. Especially the costs of possible legal actions induce uncertainty.

Conclusions The differing requirements between market areas may hinder export, and hence the globally operating machine manufacturing companies need tools and practices for recognising and applying safety requirements more effectively. In addition, the proposed Transatlantic Trade and Investment Partnership (TTIP) between the EU and the US can have significant effects on the field of requirements as well as the legislative framework in the future.

\section{PRODUCT RELATED HEAD INJURIES IN INFANTS AND TODDLERS - STARTING POINT FOR A CAMPAIGN}

Gabriele Ellsäßer, Frank Gries. State Office of Environment, Health and Consumer Protection Brandenburg, Germany

10.1136/injuryprev-2016-042156.350
Background The highest hospitalisation rates in $<18$ ys for all injuries as well as head injuries (S0-09) according to the national report on "Injuries by Accidents, Self-harm and Violence" (Ellsaesser 2014) were observed in infants (<1 y) and toddlers (1-4 ys). Although this is valuable information for injury prevention we need detailed information on injury events. The Full Injury Database (FDS) contains product related injuries as well as the doctor's narratives. Since 2008 we have managed to implement a FDS at three major German hospitals reporting to the Brandenburg Department of Health.

Methods Monitoring of injured patient hospital admissions (< 18 ys), either at emergency or ward, based on the European IDB standard. Case analysis of a total of 5,969 head injuries according to ICD-10 (S00-S09) in the < 5-year-olds (2008-2014). An injury was considered as an injury involving a product, when a product was categorised as "triggering" the injury. In-depth analysis of the doctor's narrative.

Results Head injuries in infants made up 77\% (644) of all injuries (831). 87\% (561) of head injuries were triggered by a product. The five most frequent product related injury events were falling from/out of: \#1 changing tables 20\%/111, \#2 furniture (e.g. couches) 17\%/96, \#3 parental bed 15\%/84, \#4 buggies 7\%/40, \#5 carriers 4\%/20.These events pertained $62 \%$ of all product related head injuries (561).

Head injuries in 1-to 4-year-olds made up 56\% $(2,876)$ of all injuries $(5,183)$. $77 \%(2,222)$ were triggered by a product. The five most frequent product related injury events were falling from: \#1 stairs 12\%/257, \#2 furniture 7\%/159, \#3 parental bed 4\%/88, \#4 bunk beds 3\%/73, tricycles 2\%/54.

Conclusions Products play an important role as triggers of head injuries among young children. Age specific safety recommendations for parents and caretakers, as currently in development by the paediatric association, are an important step in reducing those injuries.

\section{CONSUMER PRODUCT SAFETY POLICY REVISITED}

Joan Ozanne-Smith. Monash University, Department of Forensic Medicine, Australia

\subsection{6/injuryprev-2016-042156.351}

Background Consumer products are associated with mutiple deaths and millions of hospital treated injuries each year in the developed world, with the health sector bearing much of the multi-billion dollar cost.

Description of the problem In Australia, as in many countries, consumer product safety is administered by multiple jurisdictions - often with blurred boundaries between jurisdictional responsibilities. Under the Australian Consumer Law (2011) - Trade Practices Amendment Act - consumer goods are defined as "goods that are intended to be used, or are of a kind likely to be used, for personal, domestic or household use or consumption". The Australian Competition and Consumer Commission administers this law as it applies to product safety, but only for certain products. Since injuries and their prevention do not follow jurisdictional boundaries, from the public health perspective, a broader response to consumer goods is desirable to include any manufactured product likely to be used by consumers.

Aims As exemplefied by Australia, to explore complexities and shortcomings of the product safety system and to propose remedies to improve the alignment of public health, public policy and the legal operating framework to enhance product safety. 